\title{
A microscopical study of the "chlorophylloid" pigment cells of the marine polychaete Eulalia viridis (L.)
}

\author{
P.M. Costa*, F. Carrapiço**, A.P. Alves de Matos*** and M.H. Costa* \\ *IMAR - Instituto do Mar, Departamento de Ciências e Engenharia do Ambiente, Faculdade de Ciências e \\ Tecnologia da Universidade Nova de Lisboa, 2829-516 Caparica, Portugal (pmcosta@fct.unl.pt) \\ **Universidade de Lisboa, Faculdade de Ciências, Departamento de Biologia Vegetal, Centro de Biologia \\ Ambiental. Bloco C2 Campo Grande, 1749-016 Lisboa, Portugal \\ ***Anatomia Patológica, Centro Hospitalar de Lisboa Central - HCC, Rua da Beneficência 8, 1069-166 Lisboa, \\ Portugal; Centro de Estudos do Ambiente e do Mar (CESAM/FCUL) - Faculdade de Ciências da Universidade \\ de Lisboa and Centro de Investigação Interdisciplinar Egas Moniz (CiiEM), Quinta da Granja , Monte de \\ Caparica, 2829-511 Caparica, Portugal
}

Animal skin pigments, often of undisclosed biochemical nature, have many functions besides signalling and camouflage: they also play a protective role against environmental stressors, from radiation and oxidative stressinducers to predators and parasites. Most pigments are not fully synthetized by animals but rather acquired from vegetable feed and often biotransformed. These intriguing pigments called the attention of researchers in the past, such as the awkward green "chlorophylloid" pigments of the marine invertebrate Bonellia, first described in the $19^{\text {th }}$ century [1]. For decades, however, research has come to a stand-still. The marine annelid Eulalia viridis (Phyllodocidae: Polychaeta), although common throughout NW Europe, has so far received little attention to the origin and function of its bright green colouration. In fact, with the exception of part of its digestive system [2] even the basic histological description of this animal is absent, as for marine annelids in general.

Adult wild E. viridis were subjected to a comprehensive microscopy study employing several fixation and staining techniques for bright-field (BF), transmission electron (TEM) and UV-epifluorescence microscopy in order to disclose the pigment cells' microanatomy and arrangement and to infer the potential origin of the pigments. Stains for bright-field microscopy included Haematoxylin and Eosin (HE), Alcian Blue-Periodic Acid/Schiff's-Haematoxylin (AB-PAS-H) and Bronner's Sudan Black. Samples were either embedded in paraffin (BF and UV microscopy) or LR White resin (BF and TEM).

The high complexity of the animals' integument was confirmed, in accordance to the scarcely known polychaete microanatomy [3]. The green colouration is chiefly caused by the presence of specialized skin cells containing minute pigment vesicles (Fig. 1A). These pigment cells are compressed between multiple types of skin cells and possess microvilli that protrude through the integument's polysaccharide-based cuticle. The vesicles themselves appear attached to the cells' tonofilaments (Fig. 1B). The vesicles are densely packed within pigment cells (Fig. 2A) and are not fluorescent, which should exclude the existence of active chlorophyll within (Fig. 2B). From this data is may be inferred that the pigments are chlorophyll-derived substances (chlorins/pheophorbides), similar to what was observed in the polychaete Chaetopterus variopedatus [4]. Oddly enough, while the latter is a filterfeeder, thus able to sequester microalgae from the water column, E. viridis is a foraging scavenger that feeds mostly on the flesh of other invertebrates. Furthermore, the animal inhabits nude rocky shores and not algal beds where its green colour would be a clear advantage, which renders further intriguing the adaptative value of this feature, however, due to some known biocidal properties of these pigments; defence should not be overruled [5].

References

1. Newbigin M.I., Quart. J. Microsc. Sci., 41:391-431, 1898.

2. Michel C., Z. Zellforsch. Mikrosk. Anat., 98:54-73, 1969.

3. Hausen H., Hydrobiologia, 535/536:25-35, 2005.

4. Kennedy G.Y. and Nicol J.A.C., Proc. R. Soc. Lond. B, 150:509-538, 1959.

5. Agius L. et al., Pure Appl. Chem., 51:1847-1864, 1979. 
P.M. Costa acknowledges the Portuguese Science and Technology Foundation (FCT) for the grant SFRH/BPD/72564/2010. The authors also thank L. Ascensão (FCUL) for the important assistance.
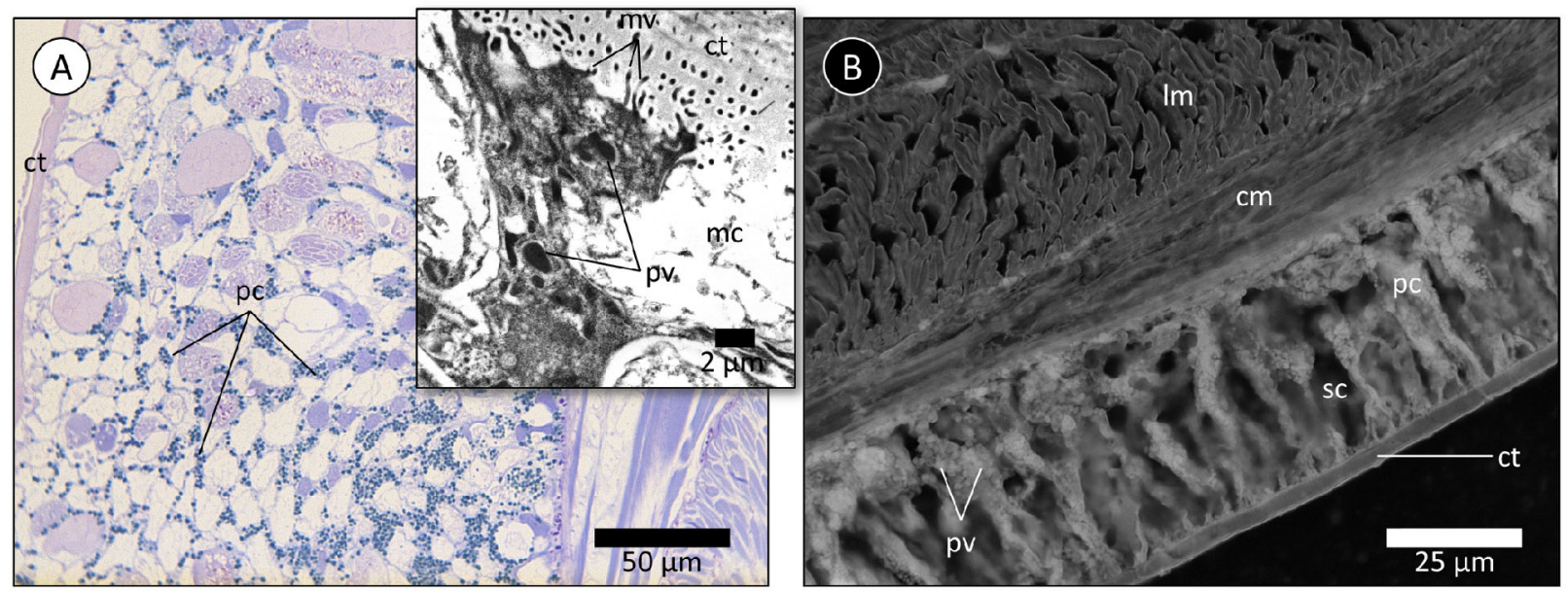

Figure 1. Example micrographs of a cross-section of E. viridis integument revealing the location of the green pigment-bearing vesicles. A) Cross-section of the cuticle-lined (ct) integument showing pigment cells (pc) compressed within a complex arrangement of multiple function epithelial cells, some of which have yet to be identified. Resin-embedded section, HE. Inset: TEM micrograph of a pigment cell compressed between mucous-secreting cells (mc) containing electron-dense pigment vesicles (pv). The pigment cell branches microvilli (mv) across the cuticle (ct). The section was fixed in Karnovsky's (cross-linking) and post-fixed with osmium tetroxide. B) Three-dimensional rendering of overlaid planes. Paraffin section of a specimen fixed in Bouin-Hollande's solution (coagulative, formalin-based), membranes stained with Bronner's Sudan Black. ct) cuticle; cm) circular musculature; $1 \mathrm{~m}$ ) longitudinal musculature; pc) pigment cells; pv) pigment vesicles; sc) secretory cells.
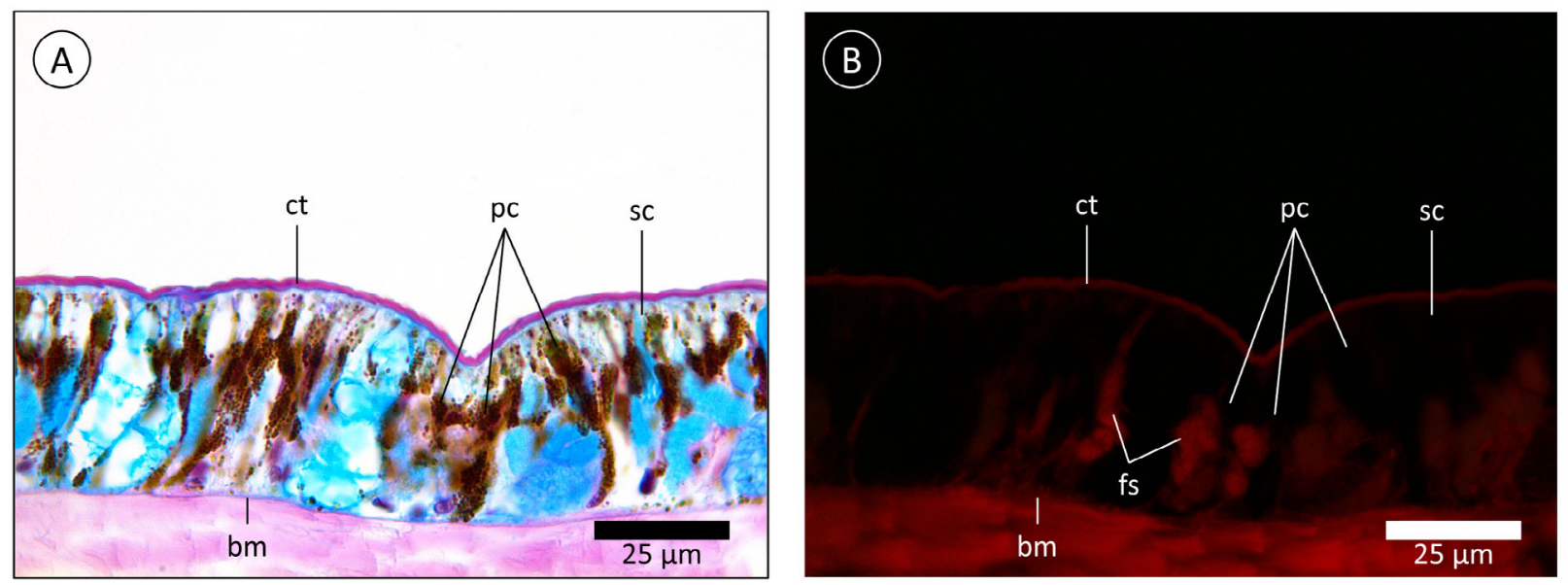

Figure 2. Integument cross section of specimen fixed in Zenker's (coagulative, mercury chloride-based) and stained with AB-PAS-H and viewed with bright-field lighting (A) and epifluorescence (B). The green pigment cells (pc) are neither fluorescent nor stained with conventional hydrophilic or lipophilic dyes such as (Haematoxylin or Sudan, respectively), unlike the cuticle layer (ct), which is strongly PAS-positive (indicating a polysaccharide-containing matrix) and some secretory cells (fs). sc) non-fluorescent, AB-positive, secretory cells (likely containing acidic polysaccharides or sialomucin-like substances); bm) skin epithelium basal membrane. 